\title{
An experimental analysis of the feeding and body weight effects of a unilateral 6-hydroxydopamine lesion of the medial forebrain bundle in the rat
}

\author{
D. C. UGURU-OKORIE \\ University of Ibadan, Ibadan, Nigeria
}

\begin{abstract}
Seventeen male Wistar albino rats were studied in terms of food intake, food spillage habits, production of feces, and body-weight regulation both before and after a unilateral microinjection of either 6-hydroxydopamine (6-OHDA) or its vehicle (isotonic saline containing $.1 \mathrm{mg} / \mathrm{ml}$ ascorbic acid) into the medial forebrain bundle (MFB). Eight subjects which sustained a total or neartotal depletion of striatal dopamine on the injected side displayed drastically reduced food intake and a steady loss of weight for 3 days after surgery, and throughout the study remained underweight, ingested less food than the controls, and spilled more food per unit amount attempted. Three subjects which sustained between $30 \%$ and $64 \%$ loss of ipsilateral striatal dopamine, as well as six vehicle-treated controls, showed no sustained loss of weight or reduction of food intake. In addition to ipsilateral striatal dopamine loss, however, marked and consistent reductions of ipsilateral striatal norepinephrine and mesolimbic dopamine were observed in the experimental subjects. All subjects lost weight substantially following $24 \mathrm{~h}$ of food deprivation and displayed increased food intake when food was restored, but the lesioned group still ingested significantly less than the control group. It is suggested that a mechanism by which unilateral 6-OHDA-induced damage of the MFB produces a sustained deficit in food intake may be the reduction of the animal's body-weight set point.
\end{abstract}

Although a detailed analysis of the nature of nigrostriatal dopaminergic involvement in ingestive behavior and body-weight regulation has not been published, it is known that these functions are seriously disrupted following nigrostriatal damage.

Bilateral lesions that interrupt the nigrostriatal DA pathway in rats produce aphagia and adipsia in the acute phase and also a constellation of long-term regulatory deficits in eating and drinking (Fibiger, Zis, \& McGeer, 1973a, 1973b; Marshall, Richardson, \& Teitelbaum, 1974; Ungerstedt, 1971; Zigmond \& Stricker, 1972). Animals with such lesions exhibit marked weight loss during the early postoperative days (Marshall, Richardson, \& Teitelbaum, 1974; Oltmans \& Harvey, 1976; Ungerstedt, 1971), and thereafter maintain their weights at levels lower than those of unlesioned controls (Boyle \& Keesey, 1975; Powley \&

This study was carried out in the laboratories of the M.R.C. Brain Metabolism Unit, Edinburgh, as part of a PhD project. The author wishes to acknowledge, with deep gratitude, the immense help received during the study from Professor David M. Vowles, Head of the Department of Psychology, University of Edinburgh, from Dr. Gordon W. Arbuthnott of the M.R.C. Brain Metabolism Unit, Edinburgh, and from their two departments. Professor Vowles's constant encouragement throughout the study is especially appreciated. Many thanks are also due to Mrs. Janet Panther, of the Department of Psychology, University of Edinburgh, for kindly doing the secretarial work. The author is at present a lecturer in the Department of Psychology of the University of Ibadan, Nigeria.
Keesey, 1970). The weight deficit in the lesioned animals appears to be a phenomenon that can be explained in terms of their refusal to eat or drink in the early postoperative days (Marshall et al., 1974; Powley \& Keesey, 1970).

It has been shown that a unilateral electrolytic lesion of the substantia nigra produces short-term impairments in food and water intake (Fibiger, Philips, \& Clouston, 1973). In the same experiment, Fibiger and his co-workers failed, however, to cause deficits in ad-lib food and water intake through unilateral 6-OHDA microinjection into the substantia nigra of another group of rats. More recently, Baez, Ahlskog, and Randall (1977) have observed severe weight loss following a unilateral nigrostriatal lesion which was induced by administering 6-OHDA directly into the MFB. Baez and his colleagues proposed that the weight loss displayed by their rats after unilateral 6-OHDA disruption of the nigrostriatal pathway was associated with impairments in food intake; but they did not directly measure this.

Since body weight depends in part upon food and water intake, it is no surprise that the body weight deficit displayed by animals sustaining an extensive lesion of the nigrostriatal DA system is supposed to be related to lesion-induced deficits in food and water intake.

The present study was designed to tackle questions pertaining to the precise nature of the weight loss and 
related phenomena associated with 6-OHDA-induced degeneration of the nigrostriatal DA system. The specific questions dealt with include: (1) Do rats with a unilateral lesion of the nigrostriatal DA system display a deficit in body weight? (2) Do they eat less than controls? (3) If there is an ingestive deficit, by what mechanism(s) is such a deficit inflicted upon the lesioned animal? (4) Do lesioned animals suffer a metabolic impairment that may be reflected in the amount of feces produced per unit amount of food ingested?

\section{METHODS}

\section{Subjects}

The subjects were 17 male Wistar albino rats weighing 180 to $200 \mathrm{~g}$ at the time of surgery. On arrival in the laboratory, the animals were housed on a reverse daylight schedule in individual cages which permitted the separate measurement of food intake, food spillage, and feces. Throughout the investigation, except when they were deprived of food for a predetermined period of time in order that their reactions and responses to food deprivation could be observed, the subjects had food and water ad lib.

\section{Preoperative and Postoperative Feeding and Body Weight}

The subjects were left undisturbed in the experimental housing conditions for 7 days before the commencement of recorded observations. Following the environmental orientation period, the actual investigational operations were begun by providing known quantities of Oxoid-modified 41B diet and water for each subject. Thereafter, measurements of food spilled, food missing from the food-hopper, water missing from the water bottle, feces produced, and the animal's body weight were taken at regular times each day.

The subjects were observed for 7 days in this fashion and then taken to the theater for surgical operation. Surgery was completed for all subjects within $4 \mathrm{~h}$ after the measurements were recorded for the 7th day. Food and water were restored at the end of surgery, and the subjects were left for $16 \mathrm{~h}$ to recover from the trauma of surgery.

The period of 16-20 $\mathrm{h}$ was fixed arbitrarily, since it is not known precisely how long the acute trauma of surgery lasts. No measurements were taken during the so-called recovery period.

The early postoperative phase of data-gathering observation began with the preparation of the cage and the provision of food and water in exactly the same manner as before surgery. The first postoperative measurements were taken $44 \mathrm{~h}$ after the completion of surgery.

The early postoperative phase of data collection comprised a fortnight of routine daily measurements of food and water consumption, food spillage, feces production, and body weight. When the measurements were completed for the 14th postoperative day, the subjects were deprived of food for $24 \mathrm{~h}$ and weight loss was determined. Then food was restored. Twenty-four hours after food-restoration, a full data-gathering session, which included the usual measurements of food and water intake, food spillage, and feces, as well as body weight, was carried out.

\section{Surgery}

The animals were anesthetized by being placed in an air-tight box through which a saturated Fluothane/air mixture was circulated. When a subject could no longer respond vigorously to a gentle squeeze of its hind paws it was adjudged anesthetized and was quickly transferred to a David Kopf stereotaxic instrument, where it was held and a mask fitted over its snout. The anesthetic mixture was steadily circulated through the mask at concentrations (about 1\%) necessary to keep the subject anesthetized while the operation proceeded. A saggittal knife-cut was made in the skin of the animal's head. After the required area of the skull was cleaned by scraping, a hole, about $2 \mathrm{~mm}$ in diameter, was made with a dental drill and the membranes covering the cortex were carefully removed. A 30-ga stainless steel cannula attached to a Hamilton syringe was lowered through the hole into the medial forebrain bundle using the following coordinates: $4.1 \mathrm{~mm}$ behind the bregma; $1.1 \mathrm{~mm}$ lateral to the midline, and $7.6 \mathrm{~mm}$ below the cortical surface. 6-OHDA hydrochloride dissolved in isotonic saline that contained $.1 \mathrm{mg} / \mathrm{ml} 1$-ascorbic acid was administered to 11 experimental subjects, each receiving a single dose of $8 \mu \mathrm{g}$ in $4 \mu \mathrm{l}$ of the vehicle at the rate of $1 \mu \mathrm{l} / \mathrm{min}$. Six control subjects received only the vehicle solution. At the end of each injection, a period of $4 \mathrm{~min}$ was allowed to elapse before the cannula was removed. The hole in the skull was covered with bone wax, and the wound was sprayed with an antibacterial agent (polybactrin) and sutured. All the subjects were injected with desipramine $(25 \mathrm{mg} / \mathrm{kg})$ and pargyline $(50 \mathrm{mg} / \mathrm{kg}) 30 \mathrm{~min}$ before central administration of 6-OHDA or its base vehicle.

\section{Verification of Lesion}

The subjects were killed by being stunned with a blow and decapitated. Their brains were quickly removed and four braintissue samples were dissected out from each brain as follows: left and right mesolimbic areas (olfactory tubercle, nucleus accumbens, and frontal cortex), and left and right striata. The samples were assayed for dopamine and norepinephrine contents according to the radioenzymatic method of Coyle and Henry (1973) and Palkovitz, Brownstein, Saavedva, and Axelrod (1974).

\section{RESULTS}

\section{Feeding Behavior and Body Weight Regulation}

Because of irregularities in the measurement of water intake in this experiment, the data collected in respect to this aspect of ingestive behavior are not presented. However, observations relating to body weight, food intake, food spillage, and feces were carefully made, and the results are presented here.

Eight subjects sustaining an extensive lesion of the nigrostriatal DA bundle, as confirmed by catecholamine assay results, displayed dramatic changes in their feeding behavior and body weight regulation. The three partially lesioned subjects and the six control subjects, on the other hand, did not exhibit any observable modification of their feeding behavior or their body-weight control. Therefore, in presenting the results of the study, the partially lesioned subjects are considered along with the controls to form a control group of nine subjects, and the eight successfully lesioned subjects constitute the experimental group.

The results are presented for the most part in terms of records taken over periods of 7 days as follows: 1 week before surgery, 1st postoperative week, and 2nd postoperative week. However, the acute effects of surgery and the animals' reactions and responses to food deprivation are presented from a single day's record.

As Figure 1 shows, the body weights of the experimental and control groups of subjects (measured in grams) were similar before surgery, but following surgery the experimental group suffered a drop in body weight, which was sustained; these subjects did not manage to catch up with the control group while the observation period lasted. 

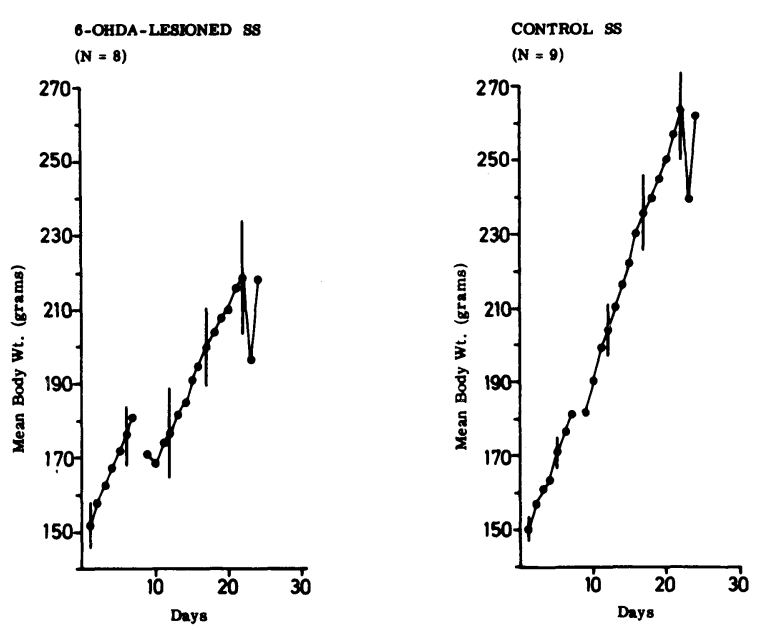

Figure 1. Mean body weights displayed from day to day by rats with a unilateral 6-OHDA induced lesion of the medial forebrain bundle and by controls. The two groups of subjects were similar in mean body weights prior to surgery, but for 3 days after surgery the experimental group suffered a steady loss of weight and thereafter remained underweight relative to the control group. The bars represent the standard deviations (SD) on the days indicated. The SDs were computed for each day of the study, but for the sake of clarity only a few are shown in the graph.

Table 1 shows the mean increase in body weight displayed by the two subject groups over periods of 7 days just before surgery and 2 weeks after surgery. Statistical treatment of the data, using the MannWhitney U test (Auble, 1953; Mann \& Whitney, 1947), revealed no significant difference between the two groups before surgery. On the other hand, a similar statistical treatment of the postoperative data showed that the experimental subjects gained a significantly smaller amount of weight than did the control subjects during the 1st postoperative week $(p=.001$, one-tailed test) and during the 2 nd postoperative week $(p=.01$, onetailed test).

Records were not taken on the day immediately following surgery. However, the first postoperative records (taken $44 \mathrm{~h}$ after surgery) showed that while seven of the nine control subjects had regained their preoperative highest recorded body weights, the experimental subjects had not made a similar recovery, except in the case of the animal with only an $86 \%$ loss of striatal DA on the lesioned side (Table 2). The difference between the two groups in weight gained over the 44-h period between surgery and the first postoperative record is statistically significant $(\mathrm{p}<.001$, Mann-Whitney $U$ test, one-tailed). On the other hand, there was not a significant difference between the two groups of subjects in weight loss as a result of 24-h food deprivation, or in weight recovery (= amount of weight gained) $24 \mathrm{~h}$ after the restoration of food, or in total weight gain recorded over these $48 \mathrm{~h}$ taken together.

Table 3 shows the body-weight changes in the fooddeprivation and food-restoration periods; the table also gives the total weight gain displayed over these $48 \mathrm{~h}$ taken together.

Food intake (that is, absolute amount in grams of food actually eaten) was not significantly different between the experimental and control groups prior to surgery (Mann-Whitney U test). Postoperatively, on the other hand, the experimental group ate significantly smaller quantities of food than the control group during the 1 st postoperative week ( $p<.001$, onetailed test), during the 2nd postoperative week ( $p<.001$, one-tailed test), and during the $24 \mathrm{~h}$ of poststarvation feeding ( $p<.001$, one-tailed test). Statistical analysis of data was by the Mann-Whitney $U$ test in all postoperative stages, as in the preoperative stage of the investigation. The food intakes of the experimental and control groups, recorded in grams, over the various periods just referred to are presented in Table 4.

Table 1

Means and Standard Deviations (in Grams) of Weight Gained by Rats With a Unilateral Microinjection of 6-OHDA Into the MFB and by Controls in the Immediate Preoperative Week, 1st Postoperative Week, and 2nd Postoperative Week

\begin{tabular}{lccccc}
\hline & \multicolumn{3}{c}{ Subject Group } \\
\cline { 2 - 3 } \multicolumn{1}{c}{ Period } & $\begin{array}{c}\text { Experimental } \\
(\mathrm{N}=8)\end{array}$ & & $\begin{array}{c}\text { Control } \\
(\mathrm{N}=9)\end{array}$ \\
\cline { 2 - 5 } \cline { 5 - 6 } & Mean & SD & Mean & SD \\
\hline Immediate Preoperative Week & 29 & 2 & 30 & 2 \\
1st Postoperative Week* & 20 & 9 & 39 & 4 \\
2nd Postoperative Week** & 24 & 7 & 34 & 7 \\
\hline
\end{tabular}

Note-First postoperative week means the 7-day period following the record taken $44 \mathrm{~h}$ after surgery.

${ }^{*} p=.001$ (Mann-Whitney U test, one-tailed).

$* * p=.01$ (Mann-Whitney U test, one-tailed).

Table 2

Weight (in Grams) Gained in $\mathbf{4} 4 \mathrm{~h}$ After Surgery

\begin{tabular}{ccccc}
\hline \multicolumn{2}{c}{$\begin{array}{c}\text { Experimental Group } \\
\text { (6-OHDA Lesioned) }\end{array}$} & & \multicolumn{2}{c}{$\begin{array}{c}\text { Control Group (Partially } \\
\text { Lesioned and Unlesioned) }\end{array}$} \\
\cline { 1 - 2 } Subject & Weight Gain & & Subject & Weight Gain \\
\hline A & -14.7 & & A $^{*}$ & 6.5 \\
B & -20.5 & & B $^{*}$ & 6.4 \\
C & -10.0 & & C $^{*}$ & .0 \\
D & -1.3 & & D & 2.6 \\
E & -6.6 & & E & .7 \\
F & -15.5 & & F & 1.8 \\
G & -14.5 & & G & -.6 \\
H & .5 & & H & .5 \\
& & & I & -1.3 \\
Mean & -10 & & Mean & 2 \\
SD & 7 & SD & 3 \\
\hline
\end{tabular}

Note-The difference between the experimental and control groups is significant ( $p<.001$, Mann-Whitney U test, one-tailed). In the experimental group, only Subject $H$ displayed an increase in this period; in this regard, it should be noted that whereas all the other experimental subjects suffered 100\% depletion of striatal $D A$ on the lesion side, this particular animal retained $14 \%$ of the DA content of its ipsilateral striatum.

*Partially lesioned control subjects. 
Table 3

Weight Changes (in Grams) Observed Following Food Deprivation and $24 \mathrm{~h}$ After Food Restoration

\begin{tabular}{|c|c|c|c|}
\hline Subject & $\begin{array}{l}\text { Weight Lost } \\
\text { During } \\
\text { Food Depri- } \\
\text { vation }\end{array}$ & $\begin{array}{l}\text { Weight Gained } \\
24 \text { h After } \\
\text { Food Restor- } \\
\text { ation }\end{array}$ & $\begin{array}{c}\text { Total } \\
\text { Weight } \\
\text { Gain }(48 \mathrm{~h})\end{array}$ \\
\hline & \multicolumn{3}{|c|}{$\begin{array}{l}\text { Experimental Group } \\
\text { (6-OHDA Lesioned) }\end{array}$} \\
\hline $\mathbf{A}$ & 23.3 & 24.1 & .8 \\
\hline B & 23.3 & 24.4 & 1.1 \\
\hline $\mathrm{C}$ & 23.6 & 24.0 & .4 \\
\hline D & 26.7 & 23.9 & -2.8 \\
\hline E & 14.4 & 21.7 & 7.3 \\
\hline $\mathbf{F}$ & 27.5 & 19.8 & -7.7 \\
\hline G & 24.8 & 20.3 & -4.5 \\
\hline $\mathrm{H}$ & 24.0 & 17.9 & -6.1 \\
\hline Mean & 23 & 22 & 1.4 \\
\hline \multirow[t]{2}{*}{ SD } & 4 & 2 & 5 \\
\hline & \multicolumn{3}{|c|}{$\begin{array}{l}\text { Control Group } \\
\text { (Partially Lesioned and Unlesioned) }\end{array}$} \\
\hline$A^{*}$ & 29.0 & 26.2 & -2.8 \\
\hline B* & 30.2 & 26.5 & -3.7 \\
\hline$C^{*}$ & 25.5 & 25.1 & -.4 \\
\hline D & 21.0 & 18.7 & -2.3 \\
\hline $\mathbf{E}$ & 24.0 & 20.9 & -3.1 \\
\hline $\mathrm{F}$ & 25.8 & 20.8 & -5.0 \\
\hline G & 25.2 & 20.5 & -4.7 \\
\hline $\mathrm{H}$ & 25.1 & 24.5 & -.6 \\
\hline I & 30.3 & 24.9 & -5.4 \\
\hline Mean & 26 & 23 & -3 \\
\hline SD & 3 & 3 & 2 \\
\hline
\end{tabular}

Note-The differences between the experimental and control groups were not statistically significant (Mann-Whitney $U$ test). *Partially lesioned control subjects.

The spillage of food in the process of consumption did not show a significant difference between the experimental and control groups of subjects preoperatively when compared statistically, using the MannWhitney U test. A similar statistical comparison of postoperative food-spillage habits, on the other hand, revealed that the experimental group spilled much more food in the course of feeding than did the control group. Since the quantity of food spilled by an animal depends, in the final analysis, upon the quantity removed from the food-hopper for the purpose of feeding, it was judged more meaningful to treat food spillage in terms of the ratios of food spilled to food missing from the food-hopper than in terms of the absolute quantities of food spilled. Table 5 shows the mean ratios for the experimental and control groups in the week preceding surgery, during the 1 st postoperative week, during the 2 nd postoperative week, and during the $24 \mathrm{~h}$ of poststarvation feeding. All the postoperative records showed a significant difference between the two groups of subjects ( $p<.001$, Mann-Whitney U test, one-tailed).

The production of feces was judged to be more meaningfully presented in terms of the ratio of feces passed to food actually ingested than in terms of the absolute quantity (i.e., weight) of feces passed, since the quantity of feces produced is determined partly by food intake. It was assumed that the more food an animal ingests, the greater the quantity of feces it produces. This assumption is obviously true to a point. Moreover, in the author's experience, there is a certain amount of consistency among normal rats of the same age in the relationship between quantity of feces passed and quantity of food ingested over a period of 3 or more days.

The mean ratios of feces passed to food ingested by the experimental and control groups of subjects are shown in Table 6, as recorded for 1 week just before surgery, for the 1st postoperative observation week, and for the 2nd postoperative observation week. There was not a significant difference between the two groups of subjects in any of these periods of recorded observation (Mann-Whitney U test).

\section{Catecholamine Assay Results}

The DA and NE assay results are presented in Table 7 . Of the 11 subjects given a unilateral microinjection of 6-OHDA aimed at the MFB, 7 sustained a DA depletion of $100 \%$ and 1 subject sustained an $86 \%$ loss; the drop in ipsilateral striatal DA content suffered by the remaining 3 subjects ranged from $30 \%$ to $64 \%$. As Table 7 shows, 6-OHDA microinjection also caused reductions in the NE content of the denervated striatum and in the DA content of the corresponding mesolimbic region, although mesolimbic NE was unaffected in five of the eight subjects sustaining a substantial loss of DA in the ipsilateral striatum. The six control subjects did not show a consistent drop to any degree at all in the DA or NE content of the ipsilateral striatum or mesolimbic region.

Table 4

Means and Standard Deviations (in Grams) of Food Intake by Rats With a Unilateral 6-OHDA Lesion of the Nigrostriatal DA Pathway and Controls

\begin{tabular}{|c|c|c|c|c|c|c|}
\hline \multirow[b]{2}{*}{ Period } & \multicolumn{3}{|c|}{ Experimental Group } & \multicolumn{3}{|c|}{ Control Group } \\
\hline & Mean & SD & $\mathbf{N}$ & Mean & SD & $\mathbf{N}$ \\
\hline Immediate Preoperative Week & 150 & 9 & 8 & 147 & 10 & 9 \\
\hline 1st Postoperative Week* & 112 & 25 & 8 & 161 & 13 & 9 \\
\hline 2nd Postoperative Week* & 149 & 16 & 8 & 195 & 11 & 9 \\
\hline $24 \mathrm{~h}$ of Feeding Following a Period of Food Deprivation* & 28 & 3 & 8 & 35 & 2 & 9 \\
\hline
\end{tabular}

${ }^{*} p=.001$ (Mann-Whitney U test, one-tailed). 
Table 5

Means and Standard Deviations (in Grams) of Ratios of Food Spilled to Food Bitten Off in the Process of Feeding by the Experimental (6-OHDA-Lesioned) and Control (Partially Lesioned and Unlesioned) Groups of Subjects

\begin{tabular}{|c|c|c|c|c|c|c|}
\hline \multirow[b]{2}{*}{ Period } & \multicolumn{3}{|c|}{ Experimental Group } & \multicolumn{3}{|c|}{ Control Group } \\
\hline & Mean & SD & $\mathrm{N}$ & Mean & SD & $\mathbf{N}$ \\
\hline Immediate Preoperative Week & .14 & .01 & 8 & .14 & .03 & 9 \\
\hline 1st Postoperative Week* & .34 & .10 & 8 & .16 & .02 & 9 \\
\hline 2nd Postoperative Week* & .33 & .10 & 8 & .16 & .02 & 9 \\
\hline 24 h of Feeding Following a Period of Food Deprivation & .32 & .11 & 8 & .15 & .03 & 9 \\
\hline
\end{tabular}

${ }^{*} p<.001$ (Mann-Whitney U test, one-tailed).

\section{DISCUSSION}

The observation that rats sustaining an extensive unilateral lesion of the nigrostriatal DA system as a result of 6-OHDA microinjection into the MFB lost weight substantially and remained underweight for a long time (Figure 1) confirms the finding of Baez et al. (1977). Also, the finding that such animals ate significantly less food than injected controls supports the suggestion by these authors that the observed effect of lesion on body weight was due to reduced food intake.

Every one of the lesioned animals spilled more food than any of the controls per unit amount bitten off in the process of feeding (Table 5). It may be that the observed reduction in actual food intake was due, at least in part, to sensorimotor dysfunction reflected in increased food spillage, considering that nigrostriatal damage disrupts sensorimotor functioning (Marshall et al., 1974). It should be mentioned also that some of the lesioned animals consistently bit off more food than controls in the process of feeding. This may represent an effort to make up for the huge amounts lost through spillage. It might be argued, therefore, that the reduction of food intake following lesion was not associated with any impairment of motivation but was ultimately due to a disruption of sensorimotor functioning. However, it seems important to note that following $24 \mathrm{~h}$ of food deprivation, all subjects, lesioned and unlesioned alike, ingested more food in one day than they ever did in a com-

Table 6

Means and Standard Deviations of Ratios of Feces Passed to Food Actually Ingested by Rats With a Unilateral Microinjection of 6-OHDA Into the MFB and by Controls

\begin{tabular}{lcccccc}
\hline & \multicolumn{4}{c}{ Subject Group } \\
\cline { 2 - 5 } \multicolumn{1}{c}{ Period } & \multicolumn{3}{c}{ Experimental } & \multicolumn{3}{c}{ Control } \\
\cline { 2 - 6 } \cline { 5 - 6 } & Mean & SD & N & Mean & SD & N \\
\hline Immediate Preoperative Week & .35 & .04 & 8 & .35 & .30 & 9 \\
1st Postoperative Week & .34 & .04 & 8 & .36 & .02 & 9 \\
2nd Postoperative Week & .34 & .03 & 8 & .36 & .03 & 9 \\
\hline
\end{tabular}

Note-The differences between the experimental and control groups are not statistically significant (Mann-Whitney $U$ test).
Table 7

Percent Catecholamine Loss in the Injected Hemisphere of 6-OHDA-Lesioned and Control Rats

\begin{tabular}{ccccc}
\hline & \multicolumn{2}{c}{ Dopamine } & \multicolumn{2}{c}{ Norepinephrine } \\
\cline { 2 - 5 } Subject & Striatum & Mesolimbic & Striatum & Mesolimbic \\
\hline \multicolumn{4}{c}{ Experimental Group } \\
(6-OHDA Lesioned) \\
A & 100 & 96 & 93 & 0 \\
B & 100 & 100 & 95 & 0 \\
C & 100 & 100 & 86 & 75 \\
D & 100 & 97 & 88 & 42 \\
E & 100 & 96 & 91 & 0 \\
F & 100 & 99 & 97 & 82 \\
G & 100 & 100 & 99 & 0 \\
H & 86 & 95 & 65 & 0 \\
& \multicolumn{4}{c}{ Control Group } \\
A & (Partially Lesioned and Unlesioned) \\
A & 64 & 14 & 54 & 0 \\
B* & 31 & 10 & 20 & 6 \\
C* & 30 & 11 & 22 & 4 \\
D & 18 & 0 & 0 & 1 \\
E & 0 & 6 & 8 & 0 \\
F & 9 & 3 & 20 & 26 \\
G & 3 & 28 & 0 & 31 \\
H & 0 & 0 & 27 & 0 \\
I & 9 & 14 & 0 & 33 \\
\hline
\end{tabular}

*Partially lesioned control subjects.

parable period under conditions of unlimited food availability. Although unlesioned animals ate significantly more food than lesioned ones following food deprivation as well as under ad-lib conditions, it is interesting that, under suitable conditions, the lesioned subjects exceeded their usual level of food intake in spite of their sensorimotor disability. In light of this observation, it seems reasonable to conclude that restriction of food intake by the lesioned animals was not imposed by sensorimotor dysfunction alone. It would appear that the animals ate more following food deprivation in order to make up for something lost and that under conditions of ad-lib food supply they did not need to eat so much.

As Figure 1 shows, the lesioned group suffered a substantial loss of weight after surgery and, for some time, displayed a lower rate of weight increase than controls. In the meantime, these animals ate less food than controls from day to day. It may be that animals indeed eat to reach and maintain a target level in 
body weight (Powley \& Keesey, 1970; Teitelbaum, 1961). If so, it may be that a unilateral MFB lesion of the kind used in this study imposes a new, reduced pattern of weight targets on an animal; and it may be that an animal's weight target, along with certain other physiological factors not investigated in the present study, determines the amount of food ingested. Because the body weight target is lower in lesioned animals than in controls, the lesioned animals would need less food and so would consume less.

The weight-target principle appears to account for the fact that lesioned animals eat more food than usual following food deprivation-an observation that cannot be explained adequately in terms of a model based upon the concept of sensorimotor impairment.

The finding that lesioned animals pass roughly the same quantity of feces as controls per unit amount of food ingested (Table 6) shows that the "utilization" of food at the level of the alimentary tract is not impaired by a unilateral 6-OHDA lesion of the MFB. It does not, though, exclude the possibility that such a lesion might be accompanied by a disruption of the assimilation stage of the food-utilization process. This, in fact, is a possibility worth investigating.

Judging strictly from the results of the present study, therefore, it seems reasonable to draw the following conclusions: (1) Rats with a unilateral 6-OHDA lesion of the MFB display a deficit in body weight; (2) they eat less than controls; (3) the reduction of food intake observed in such animals may be due in part to an impairment of the sensorimotor component of ingestive behavior; (4) this ingestive deficit may also be due, in part, to a lowering of their body weight targets; however, (5) there seems to be no metabolic change that is reflected in the amount of feces produced per unit amount of food ingested.

In Table 7, it can be seen that the microinjection of 6-OHDA into the MFB led to a huge drop in the DA content of the striatum on the injected side. However, there were also consistent depletions of striatal $\mathrm{NE}$ and mesolimbic DA. It is, therefore, not possible to conclude, on the strength of the results of the present study, that any behavioral effects attributable to the lesion procedure were due exclusively, or even in part, to the disruption of the nigrostriatal DA system. Nigrostriatal dopaminergic involvement is, however, more than a possibility, since the most pronounced neurochemical effect of the lesion is seen in the striatal DA level. Moreover, the nigrostriatal DA pathway is intimately associated with the extrapyramidal system (Bedard, Larochelle, Parent, \& Poirier, 1969), a network importantly involved in motor control (Poirier, 1976). Further work has been designed to try to clarify the degree of importance of the role played by the nigrostriatal DA system in the behavioral functions disrupted by 6-OHDA microinjection into the MFB and to define the mechanisms of such a role.

\section{REFERENCES}

Auble, D. Extended tables for the Mann-Whitney statistic. Bulletin of the Institute of Educational Research at Indiana University, 1953, 1, No. 2.

Baez, L. A., Ahlskog, J. E., \& Randall, P. K. Body weight and regulatory deficits following unilateral nigrostriatal lesions. Brain Research, 1977, 132, 467-476.

Bedard, P., Larochelle, L., Parent, A., \& Poirier, L. J. The nigrostriatal pathway: A correlative study based on neuroanatomical and neurochemical criteria in the cat and the monkey. Experimental Neurology, 1969, 25, 365-377.

Boyle, P. C., \& Keesey, R. E. Chronically reduced body weight in rats sustaining lesions of the lateral hypothalamus and maintained on palatable diets and drinking solutions. Journal of Comparative and Physiological Psychology, 1975, 88, 218-223.

Coyle, J. T., \& Henry, D. Catecholamines in fetal and newborn rat brain. Journal of Neurochemistry, 1973, 21, 61-67.

Fibiger, H. C., Philips, A. G., \& Clouston, R. A. Regulatory deficits after unilateral electric or 6-hydroxydopamine lesions of the substantia nigra. American Journal of Physiology, 1973, 225, $1282-1287$.

Fibiger, H. C., Zis, A. P., \& McGeer, E. G. Feeding and drinking deficits after 6-hydroxydopamine administration in the rat: Similarities to the lateral hypothalamic syndrome. Brain Research, 1973, 55, 123-134. (a)

Fibiger, H. C., Zis, A. P., \& McGeer, E. G. Feeding and drinking deficits after 6-hydroxydopamine administration in the rat: Similarities to the lateral hypothalamic syndrome. Brain Research, 1973, 55, 135-148. (b)

ManN, H. B., \& Whitney, D. R. On a test of whether one of two random variables is stochastically larger than the other. Annals of Mathematical Statistics, 1947, 18, 52-54.

Marshall, J. F., Richardson, J. S., \& Teitelbaum, P. Nigrostriatal bundle damage and the lateral hypothalamic syndrome. Journal of Comparative and Physiological Psychology, 1974, 87, 808-830.

Marshall, J. F., \& Teitelbaum, P. A comparison of the eating response to hypothalamic and glucoprivic challenges after nigral 6-hydroxydopamine and lateral hypothalamic electrolytic lesions in rats. Brain Research, 1973, 55, 229-233.

Oltmans, G. A., \& Harvey, J. A. Lateral hypothalamic syndrome in rats: A comparison of the behavioral and neurochemical effects of lesions placed in the lateral hypothalamus and nigrostriatal bundle. Journal of Comparative and Physiological Psychology, 1976, 90, 1051-1062.

Palkovitz, M., Brownstein, M., SaAvedra, J. M., \& Axelrod, J. Norepinephrine and dopamine content of hypothalamic nuclei of the rat. Brain Research, 1974, 77, 137-149.

PoIRIER, L. J. Functional significance of the aminoaminergic extrapyramidal connections. Pharmacology \& Therapeutics (Part B), 1976, 2, 9-17.

Powley, T. L., \& Keesey, R. E. Relationship of body weight to the lateral hypothalamic feeding syndrome. Journal of Comparative and Physiological Psychology, 1970, 70, 25-36.

Teitelbaum, P. Disturbances in feeding and drinking behavior after hypothalamic lesions. In Nebraska Symposium on Motivation. Lincoln: University of Nebraska Press, 1961.

UNGERSTEDT, U. Adipsia and aphagia after 6-hydroxydopamine induced degeneration of the nigrostriatal dopamine system in the rat brain. Acta Physiologica Scandinavica, 1971, Suppl. 367, 95-122.

ZIGMOND, M. J., \& STRICKeR, E. M. Deficits in feeding behavior after intraventricular injection of 6-hydroxydopamine in rats. Science, 1972, 177, 1211-1214.

(Received for publication June 16, 1980; revision accepted October $10,1980$. 